\title{
Effect of channel geometries on two-phase mixture level swell and its fluctuation amplitude
}

\author{
Takahiro ARAI*, Masahiro FURUYA* and Kenetsu SHIRAKAWA* \\ ${ }^{*}$ Central Research Institute of Electric Power Industry \\ 2-6-1 Nagasaka, Yokosuka-shi, Kanagawa 240-0196, Japan \\ E-mail: t-arai@criepi.denken.or.jp
}

Received: 30 October 2019; Revised: 7 January 2020; Accepted: 9 March 2020

\begin{abstract}
Gas-liquid two-phase flow in a stagnant pool is an important phenomenon in designing and operating industrial facilities. When gas is mixed or boiling occurs in stagnant water, the actual water level appears higher than the original water level. The actual water level is called a two-phase mixture level and largely depends on the flow channel geometries, dimensions, and flow conditions. This study focuses on the influence of channel geometries, circular pipes and rod bundles, on the two-phase mixture level and its fluctuation behavior. An air-water experiment using circular pipes with inner diameters of 50 and $224 \mathrm{~mm}$ and $5 \times 5$ and $10 \times 10$ rod bundles was conducted, and the two-phase mixture level swell was visually observed. As the inlet gas flow rate increased, the two-phase mixture level basically increased regardless of the channel geometry. The fluctuation amplitude was remarkably increased by formulating the slug bubbles covering the entire diameter in the small pipe with a diameter of up to $50 \mathrm{~mm}$. In the rod bundles and large pipe with a diameter of $224 \mathrm{~mm}$, no slug bubble was sustained, and the two-phase water level and its fluctuation amplitude were relatively small compared with those of the small pipe.
\end{abstract}

Keywords: Two-phase mixture level, Water level swell, Circular pipe, Rod bundle, Fluctuation amplitude, Collapsed water level, Air-water two-phase flow.

\section{Introduction}

When a gas is mixed in a stagnant water pool, the actual water level is higher than the original liquid level. The actual water level is called a two-phase mixture level and depends on the volume of gas phase in the pool (the void fraction). The two-phase flow in stagnant water is complex, and the flow pattern changes significantly depending on the gas flow rate. The two-phase mixture level fluctuates as gas bubbles are released from the liquid surface. This two-phase mixture level swell is assumed in various industrial facilities (such as a reactor core and a filter venting system in nuclear power plants, and a bubble tower in chemical plants) and is related to their design and operation. A two-phase mixture level in the reactor core is formed under conditions when the water level drops with evaporation due to a loss of external water injection function (as in a nuclear plant accident). From a core cooling perspective, it is important to predict the exact location of the two-phase mixture level fluctuation; it is not possible to keep the reactor core around the saturation temperature of coolant if the core is exposed to the gas phase (Arai et al., 2015a, 2015b). In a filter venting system, a two-phase mixture level is formed in the vessel during pool scrubbing, and it is an important parameter for maintaining the appropriate operation according to assumed gas flow rate conditions.

Regarding the two-phase mixture level swell, researchers have conducted two-phase flow experiments in stagnant water (Osakabe et al., 1984; Suzuki and Murase, 1986; Kataoka et al., 1987; Kamei et al., 2010; Chen et al., 2012). Boiling experiments also have been conducted to evaluate the void fraction and actual water level during boil-off condition when water level drops due to evaporation (Shires et al., 1980; Seedy and Muralidoran, 1982; Anklam and Miller, 1983; Kumamaru et al., 1994; Qazi et al., 1994). However, those studies mainly focused on the void fraction and height of the two-phase mixture level; not enough is known about two-phase mixture level swell, such as the fluctuation amplitude of the two-phase mixture level. Ueda and Koizumi (1993) conducted an air-water flow 
experiment using vertical pipes with different diameters. They observed the two-phase mixture level swell and its fluctuation amplitude and demonstrated that the experimental results can be organized through normalization with the initial liquid level. Channel geometry and size are closely related to the two-phase flow and mixture level in a stagnant water pool. When the channel size is small or a structure such as a rod bundle exists in the flow channel, and the channel configuration consequently affects the two-phase mixture level swell and its fluctuation.

In this study, an air-water experiment was conducted in which air was supplied and mixed in a stagnant water pool using different flow channel shapes and sizes. The collapsed water level, and the air flow rate were varied as experimental parameters to clarify the correlation between the two-phase mixture level and the collapsed water level, and the effects of the channel geometries, initial liquid level, and air flow rate on the fluctuation amplitude of the two-phase mixture level.

\section{Experimental}

Figure 1 shows an air-water two-phase flow test loop that mainly comprises a circulation pump, test sections, a steam separator, and a cooler. Air is supplied from the air compressor to the test section through the buffer tank. The top of the separation tank was open to atmosphere. Four kinds of test sections were used, as shown in Table 1: vertical circular pipes with inner diameters $D$ of 50 and $224 \mathrm{~mm}$, a $5 \times 5$ rod bundle, and a $10 \times 10$ rod bundle. Small or large pipes are defined by whether slug bubbles over the entire diameter can exist. When the pipe diameter reaches the specified dimension, no slug bubbles can be sustained due to interfacial instability. The criteria of the diameter in which

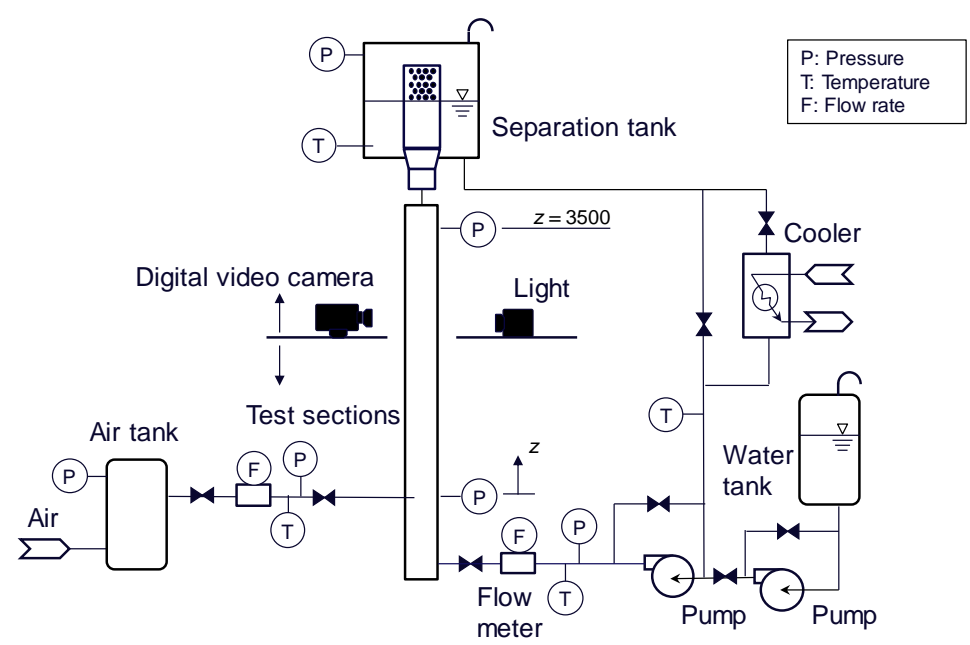

Fig. 1 Schematic of air-water two-phase flow test loop. It mainly comprises a circulation pump, test sections, a steam separator, and a cooler. The setup includes four test sections, a circular pipe $(D=50 \mathrm{~mm}, 224 \mathrm{~mm})$, and $5 \times 5$ and $10 \times 10$ rod bundles.

Table 1 Flow channel geometries.

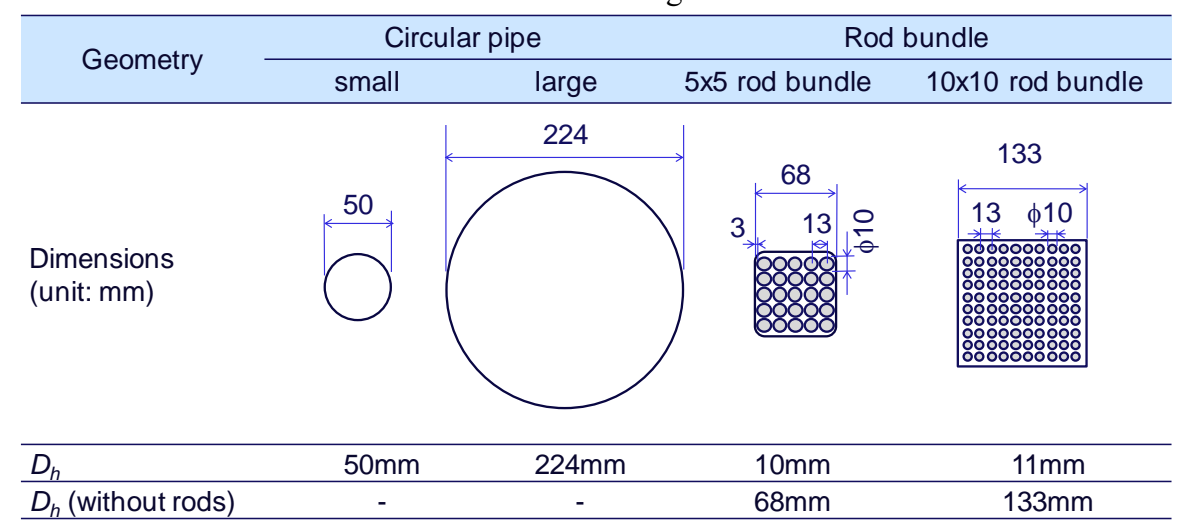


the slug bubbles cannot be sustained are described as follows (Kataoka and Ishii, 1987):

$$
D_{h}^{*}=\frac{D_{h}}{\sqrt{\frac{\sigma}{g \Delta \rho}}} \cdot \geq 40,
$$

where $D_{h}{ }^{*}$ is the nondimensional hydraulic diameter, $D_{h}$ is the hydraulic diameter, $\sigma$ is the surface tension, $\Delta \rho$ is the density difference between the two phases, and $g$ is the gravitational acceleration. Since $D_{h}{ }^{*}=40$ in an air-water two-phase flow experiment corresponds to $D_{h}=0.11 \mathrm{~m}$, the circular pipes with a diameter of 50 and $224 \mathrm{~mm}$ are called the small circular pipe and the large circular pipe, respectively. The test sections were connected to the loop in parallel. The rods in the bundles were $10 \mathrm{~mm}$ in diameter with a pitch of $13 \mathrm{~mm}$. The height of the test section was $3.5 \mathrm{~m}$ from the air injection height level. The circular pipes and channel boxes of the rod bundles were made of clear acrylic for flow visualization. Air was uniformly supplied through multiple nozzles and was mixed at the lower end of the test section.

The test parameters of this experiment were the superficial gas velocity, the collapsed water level as the initial liquid level, and the channel geometries. The experimental range was a superficial gas velocity of $j_{g}=0.02-3.5 \mathrm{~m} / \mathrm{s}$ and a collapsed water level of 300 to $1200 \mathrm{~mm}$. Ion-exchanged water was used as a test fluid at room temperature.

The experimental procedure was as follows: Water was injected into the test section, and the initial liquid level was set to a specified height before closing the inlet valve at the bottom of the test section to disconnect the water circulation system. Air was injected and mixed from the bottom of the test section into the stagnant water. The air flow rate was measured by a mass flow meter with accuracy of $3.0 \%$. The actual height of the two-phase mixture level and its fluctuation were recorded with a digital video camera for a total period of $30 \mathrm{~s}$. The video camera and light were manually traversed to visualize the fluctuation behavior from the side. Regarding the flow visualization for rod bundle, two-phase mixture level was mainly observed in the peripheral region and the rod gaps due to the existence of the metal rods.

\section{Two-phase mixture level and its fluctuation}

Figure 2 shows a conceptual diagram when gas is mixed in a stagnant pool. When the height at which the gas is injected is defined as the reference height $z=0$, the two-phase mixture level $L_{m}$ is higher than the initial liquid level and the collapsed water level $L_{c}$, according to the volume ratio of the gas phase in the pool. Intermittent fluctuation occurs with the release of bubbles from the liquid surface. In the experiment, the maximum height $L_{\max }$ and minimum height $L_{\min }$ of the two-phase mixture level was visually measured. When the two-phase mixture level fluctuation is recorded with a digital video camera from the side, the recorded images include all the information in a depth direction. When the channel size increases, the liquid surface is agitated by the passage of small and large bubbles. As the air flow rate increases, the coalesced large bubbles concentrate to the center of the flow channel and are intermittently released from

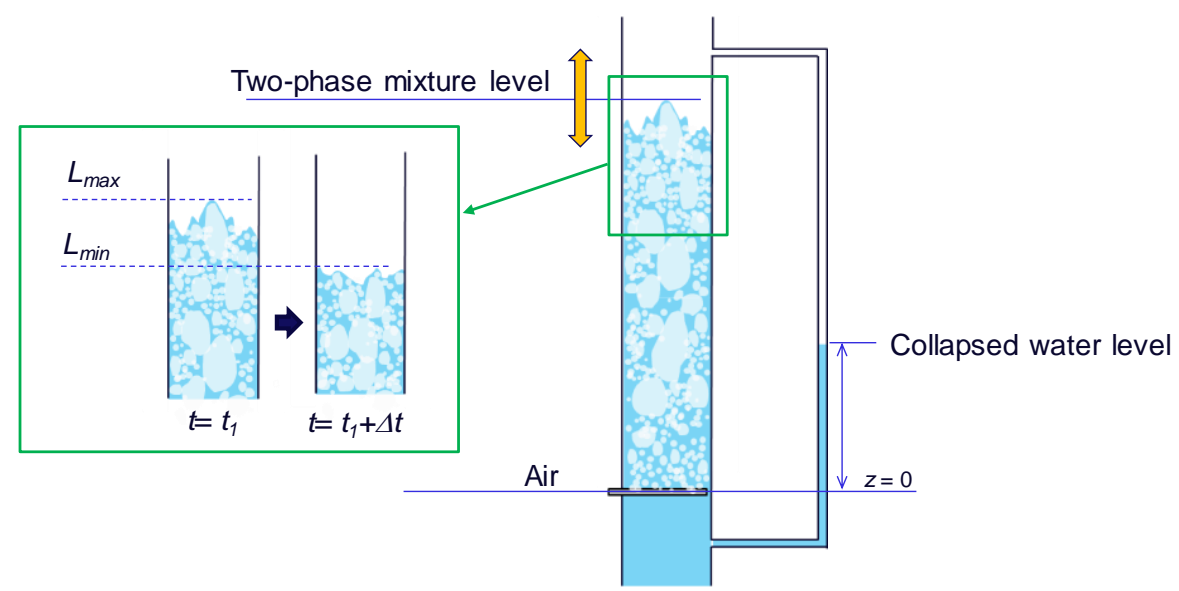

Fig. 2 Relationship of two-phase mixture level to collapsed water level. The two-phase mixture level appears to be higher than the collapsed water level according to the volume ratio of the gas phase in a pool and intermittently fluctuate with the bubble passage through the liquid surface. 
the liquid surface. The maximum and minimum heights of the two-phase mixture level tend to occur at the center of the flow channel. Therefore, the highest level on the liquid surface was defined as the two-phase water level at that time. The maximum and minimum values of the two-phase mixture level during the recording time were defined as $L_{m a x}$ and $L_{\text {min }}$, respectively. When identifying the two-phase mixture level using image processing, background information is initially removed from the original image, and the intensity values in the horizontal (radial) direction in the flow channel is merged to obtain a 1D axial distribution of the intensity values. By binarizing the intensity values, we can identify the two-phase mixture level. The actual liquid surface is disturbed by splashing of liquid droplets and liquid film at the passage of bubbles and can affect the image processing. For the aforementioned reasons, the two-phase mixture level was comprehensively determined by image processing and visual observation. The fluctuation period was approximately several seconds at the longest when a slug flow was observed in the small-diameter pipe. The recording time of $30 \mathrm{~s}$ is long enough to obtain the typical fluctuation of the two-phase mixture level in the experiment.

The average height of the two-phase mixture level $L_{m}$ was calculated as follows:

$$
L_{m}=\frac{L_{\max }+L_{\min }}{2}
$$

The fluctuation amplitude of the two-phase mixture level is defined as follows:

$$
\Delta L=\frac{L_{\max }-L_{\min }}{2}
$$

Ueda and Koizumi (1993) defined the averaged two-phase mixture level and its fluctuation amplitude as shown in Eqs. (2) and (3) and proposed a model in small circular pipes of 10.0, 14.8, 20.2, and $26.0 \mathrm{~mm}$. In the proposed model, the relationship between $L_{c}$ and $L_{m}$ was calculated on the assumption that the shear force on the channel wall surface was negligible when air was mixed into the stagnant water pool. The void fraction can be expressed as the ratio of the superficial gas velocity to the bubble velocity. The bubble velocity is affected not only by the flow conditions but also by the flow channel configurations. To calculate the drift velocity and void fraction in consideration of the flow channels, circular pipes, and rod bundles, we applied the drift flux model (Zuber and Findlay, 1965), which is expressed as follows:

$$
\begin{aligned}
\frac{L_{m}}{L_{c}} & =\frac{1}{1-\alpha} \\
& =\frac{C_{0}\left\langle j_{g}\right\rangle+V_{g j}}{\left(C_{0}-1\right)\left\langle j_{g}\right\rangle+V_{g j}}
\end{aligned}
$$

where $\alpha$ is the volume-averaged void fraction, $C_{0}$ is the distribution parameter, $j_{g}$ is the superficial gas velocity, and $V_{g}$ is the drift velocity. $\Delta L$ is expressed as the relationship between the rising velocity of the gas plug in a vertical pipe and

$$
\frac{\Delta L}{L_{c}}=N\left(\frac{\left\langle j_{g}\right\rangle}{V_{g j}}+\frac{1}{C_{0}}\right),
$$

the downward velocity of the liquid mass just above the plug:

$$
N=\frac{\Delta h}{L_{c}} \frac{C_{0}}{\alpha_{p m}},
$$

where $\Delta h$ is the height of the liquid mass just above the gas plug and $\alpha_{p m}$ is the average void fraction of the plug. Ueda and Koizumi (1993) demonstrated that $N=0.05$ for bubbly flow and $N=0.1-0.2$ for slug flow based on the experimental data using small pipes. This paper used relatively large flow channels in its experiment, although generally it is difficult to form a gas plug over the entire flow channel as assumed in the model. However, the fluctuation amplitude of the two-phase mixture level depends on the dominant bubble scale released from the liquid surface. Therefore, it should be effective as an index for comparing the fluctuation amplitude of the water level. 
Experimental data were acquired for different flow channel configurations and a wide range of flow rate conditions. To compare the experimental data with the models, this study selected Ishii's correlations, Kataoka and Ishii's correlation, and Chen's correlation as drift flux model parameters for circular pipes and rod bundles.

The distribution parameter in the bubbly and slug flows of a circular pipe was proposed by Ishii (1977):

$$
C_{0}=1.2-0.2 \sqrt{\frac{\rho_{g}}{\rho_{l}}}
$$

in addition, Ishii (1977) proposed the drift velocities for each flow regime in a circular pipe, as follows:

For bubbly flow:

$$
V_{g j}=(1-\alpha)^{1.75} \sqrt{2}\left(\frac{g \sigma \Delta \rho}{\rho_{l}^{2}}\right)^{1 / 4}
$$

For slug flow:

$$
V_{g j}=0.35\left(\frac{g D_{h} \Delta \rho}{\rho_{l}}\right)^{1 / 2}
$$

For churn flow:

$$
V_{g j}=\sqrt{2}\left(\frac{g \sigma \Delta \rho}{\rho_{l}^{2}}\right)^{1 / 4},
$$

where $\rho_{g}$ and $\rho_{l}$ are the densities of the gas and the liquid, respectively.

Kataoka and Ishii (1987) proposed a drift flux model for pool void fraction in a large-diameter pipe, which is expressed by the following equations as parameters of the nondimensional drift flux model:

$$
\left\{\begin{array}{l}
C_{0}=1.2-0.2 \sqrt{\frac{\rho_{g}}{\rho_{l}}} \quad \text { for round tube } \\
C_{0}=1.35-0.35 \sqrt{\frac{\rho_{g}}{\rho_{l}}} \text { for rectanglar channel }
\end{array}\right.
$$

and

$$
\begin{aligned}
& \begin{cases}V_{g j}^{+}=0.0019 D_{h}^{* 0.809}\left(\frac{\rho_{g}}{\rho_{l}}\right)^{-0.157} N_{\mu f}^{-0.562} & N_{\mu l} \leq 2.25 \times 10^{-3}, D_{h}^{*} \leq 30 \\
V_{g j}^{+}=0.030\left(\frac{\rho_{g}}{\rho_{l}}\right)^{-0.157} N_{\mu l}^{-0.562} & N_{\mu l} \leq 2.25 \times 10^{-3}, D_{h}^{*} \geq 30, \\
V_{g j}^{+}=0.92\left(\frac{\rho_{g}}{\rho_{l}}\right)^{-0.157} & N_{\mu l}>2.25 \times 10^{-3}, D_{h}^{*} \geq 30\end{cases} \\
& N_{\mu l}=\frac{\mu_{l}}{\left(\rho_{l} \sigma \sqrt{\frac{\sigma}{g \Delta \rho}}\right)^{1 / 2}}, \\
& \left\langle j_{g}^{+}\right\rangle=\frac{\left\langle j_{g}\right\rangle}{\left(\frac{\sigma g \Delta \rho}{\rho_{l}^{2}}\right)^{1 / 4}}, \\
& V_{g j}^{+}=\frac{V_{g j}}{\left(\frac{\sigma g \Delta \rho}{\rho_{l}^{2}}\right)^{1 / 4}}
\end{aligned}
$$

where $\left\langle j_{g}^{+}\right\rangle$is the nondimensional superficial gas velocity, $\left\langle j_{g}\right\rangle$ is the area-averaged superficial gas velocity, $\mathrm{V}_{g j}^{+}$is the nondimensional drift velocity, and $N_{u l}$ is the viscous number.

Chen et al. (2012) proposed a drift flux model for two-phase flow in a stagnant water pool in a rod bundle, which is also expressed by the following equations as parameters of the nondimensional drift flux model: 


$$
\begin{aligned}
& C_{0}=C_{\infty}-\left(C_{\infty}-1\right) \sqrt{\frac{\rho_{g}}{\rho_{l}}}, \\
& \begin{cases}C_{\infty}=4.79\left\langle j_{g}^{+}\right\rangle+1.00 & \left\langle j_{g}^{+}\right\rangle \leq 0.5 \\
C_{\infty}=3.45 \cdot \exp \left(-0.52\left\langle j_{g}^{+}\right\rangle^{0.51}\right)+1.00 & \left\langle j_{g}^{+}\right\rangle>0.5^{\prime}\end{cases}
\end{aligned}
$$

and

$$
\begin{aligned}
& V_{g j}^{+}=V_{g j, B}^{+} \exp \left(-1.39\left\langle j_{g}^{+}\right\rangle\right)+V_{g j, C}^{+}\left[1-\exp \left(-1.39\left\langle j_{g}^{+}\right\rangle\right)\right], \\
& V_{g j, B}^{+}=\sqrt{2}[1-\langle\alpha\rangle]^{1.75}, \\
& \begin{cases}V_{g j, C}^{+}=0.0019 D_{C}^{* 0.809}\left(\frac{\rho_{g}}{\rho_{l}}\right)^{-0.157} N_{\mu f}^{-0.562} & N_{\mu l} \leq 2.25 \times 10^{-3}, D_{c}^{*} \leq 30 \\
V_{g j, C}^{+}=0.030\left(\frac{\rho_{g}}{\rho_{l}}\right)^{-0.157} N_{\mu l}^{-0.562} & N_{\mu l} \leq 2.25 \times 10^{-3}, D_{c}^{*} \geq 30, \\
V_{g j, C}^{+}=0.92\left(\frac{\rho_{g}}{\rho_{l}}\right)^{-0.157} & N_{\mu l}>2.25 \times 10^{-3}, D_{c}^{*} \geq 30\end{cases} \\
& D_{C}^{*}=\frac{D_{C}}{\sqrt{\frac{\sigma}{g \Delta \rho}}}
\end{aligned}
$$

where $C_{\infty}$ is the asymptotic value of the distribution parameter, $V_{g j, B}^{+}$is the nondimensional drift velocity for the bubbly flow, $V_{g j, C}^{+}$is the modified drift velocity considering the rod-bundle casing scale, $\langle\alpha\rangle$ is the area-averaged void fraction, $D_{c}{ }^{*}$ is the non-dimensional casing geometry, $D_{c}$ is the casing dimension. Kinoshita et al. (2015) improved the model applicable to steam-water two-phase flow at high pressure.

The averaged two-phase mixture level described in Eq. (1) is defined in the same manner as the experiment conducted by Ueda and Koizumi (1993). In some previous boil-off experiments with a heated rod bundle, however, the two-phase mixture level was estimated based on the time when the rod surface temperature maintained near the saturation temperature of water started to rise during a boil-off condition. As long as water is intermittently supplied to the heated rods by the two-phase mixture level fluctuation, the rods can be sufficiently cooled; thus, the temperature change of the rod surface should capture the upper end of the fluctuation amplitude as the two-phase water level (Arai et al., 2015a, 2015b, 2019). Therefore, differences may occur in how to capture the two-phase mixture level depending on the measurement method.

\section{Results and discussion}

Figures 3 to 6 show the two-phase mixture level and fluctuation amplitude for a small-diameter pipe, a large-diameter pipe, a $5 \times 5$ rod bundle, and a $10 \times 10$ rod bundle, respectively. The two-phase mixture level and its fluctuation amplitude were normalized by the collapsed water level. The fluctuation amplitude of the two-phase mixture level is greatly influenced by the flow pattern near the liquid surface. We identified the flow patterns near the liquid surface based on the visual observation, and classified them into four types: bubbly flow, slug flow, churn-slug flow, and churn flow. The typical flow regime map in a small-diameter pipe was proposed by Mishima et al. (1984). In a large-diameter pipe, slug bubbles over the entire diameter of the pipe cannot be sustained. The flow regime corresponding to the slug flow region in a small-diameter pipe was classified into churn-slug flow (Ohnuki and Akimoto, 2000) or cap/slug flow (Schlegel et al., 2009). A rod bundle includes two channel scales, a subchannel, and a channel box because the rods exist in the channel box. The flow condition corresponding to the slug flow in the small-diameter pipe was classified into cap-bubbly flow and cap-turbulent flow (Paranjape et al., 2008; Liu and Hibiki, 2017), or was classified into churn flow according to the visual observation in each subchannel (Mizutani et al., 2006). From the viewpoint of identifying the characteristics of the two-phase mixture level fluctuation, the flow regime in the large-diameter pipe and rod bundles were divided into bubbly flow, slug flow, churn-slug flow, and churn flow in the experiment. Bubbly flow indicates that small bubbles ranging up to $10 \mathrm{~mm}$ approximately rise in the axial direction and sometimes coalesce with neighboring bubbles. Slug flow indicates that slug bubbles over the entire dimeter of the flow 


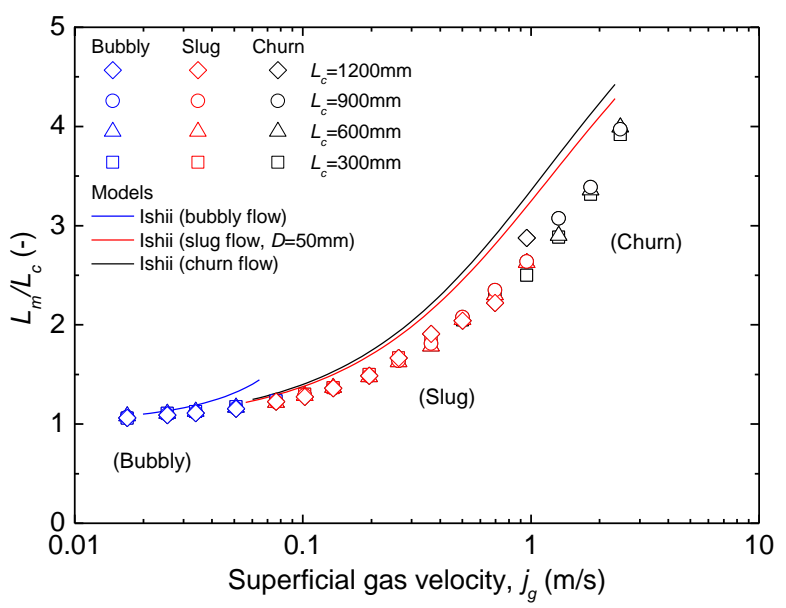

(a) Two-phase mixture level

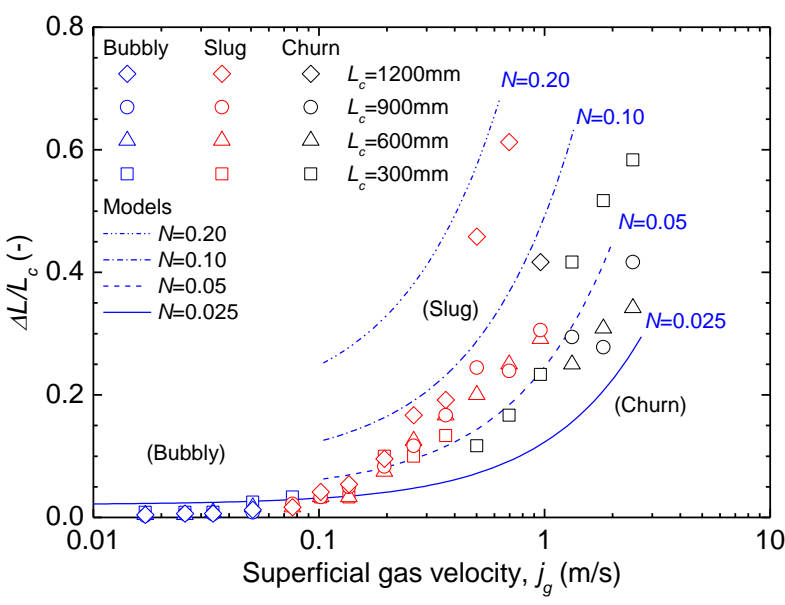

(b) Fluctuation amplitude

Fig. 3 Two-phase mixture level swell in small pipe $50 \mathrm{~mm}$ in diameter.

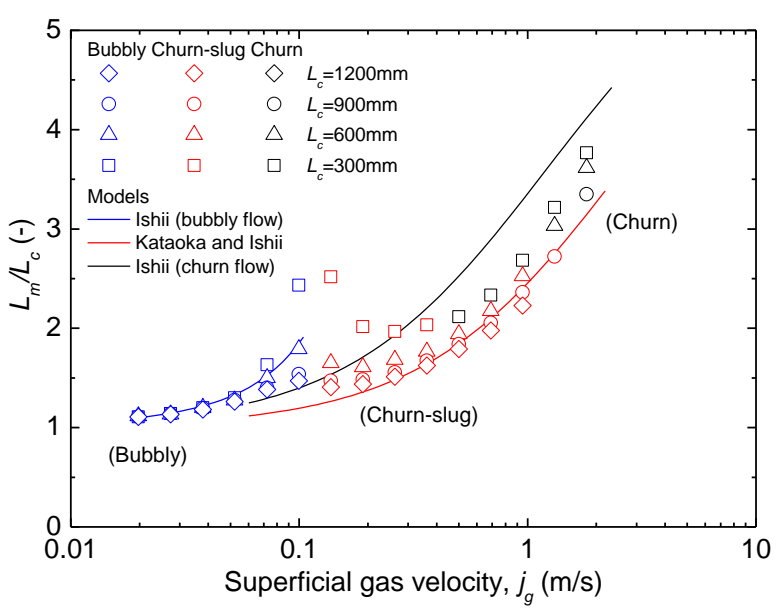

(a) Two-phase mixture level

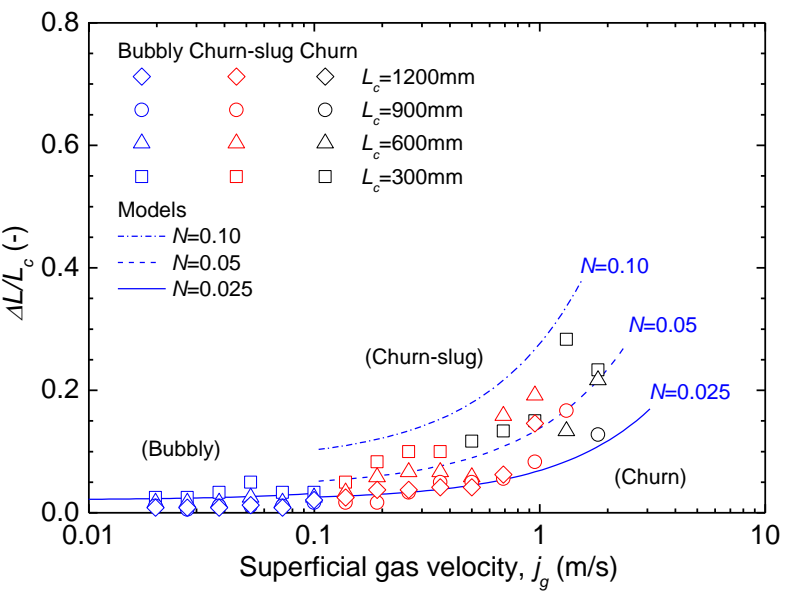

(b) Fluctuation amplitude

Fig. 4 Two-phase mixture level swell in large pipe $224 \mathrm{~mm}$ in diameter.

channel rise intermittently but were only observed in the small-diameter pipe. Churn-slug flow indicates that large bubbles intermittently move upward, and a large number of small bubbles are also observed to be turbulent. Churn flow indicates that small and large distorted bubbles move with highly agitated motion and the fluctuation amplitude relatively decreases due to the random and frequent passage of multiple large bubbles from the liquid surface. Furthermore, the fluctuation amplitude model shown in Eq. (5) assumes that a single bubble rises intermittently; thus, this paper mainly discusses bubbly flow, slug flow, and churn-slug flow.

The measurement uncertainty of the two-phase mixture level tends to be relatively larger at higher superficial gas velocity such as churn flow in the large-diameter pipe because the liquid surface is highly disturbed by splashing of liquid droplets and liquid film at the passage of bubbles. For example, when the superficial gas velocity was approximately $1.0 \mathrm{~m} / \mathrm{s}$ in the large-diameter pipe, the splash of the liquid film was observed to be approximately $80 \mathrm{~mm}$ in height, which corresponded to the uncertainty of approximately $20 \%$ with respect to the fluctuation amplitude. To reduce the measurement uncertainty as much as possible, we determined the two-phase water level by combining the image processing and visual observation. On the other hand, the bubble flow shows that dispersed small bubbles are uniformly released from the liquid surface, and the slug flow shows that slug bubbles rise upward intermittently. Therefore, the uncertainty to identify the two-phase mixture level in the bubbly flow or slug flow conditions is small enough compared with that in the churn flow.

In the circular pipes, the two-phase mixture level increased as the superficial gas velocity increased. Since the values of $L_{m} / L_{c}$ for different collapsed water levels were almost the same for all channel geometries, the influence of the initial liquid level on the two-phase mixture level was found to be small. Because this experiment involved two-phase mixing in a stagnant water pool, it was easy to reach the developed flow at the start of mixing. However, 


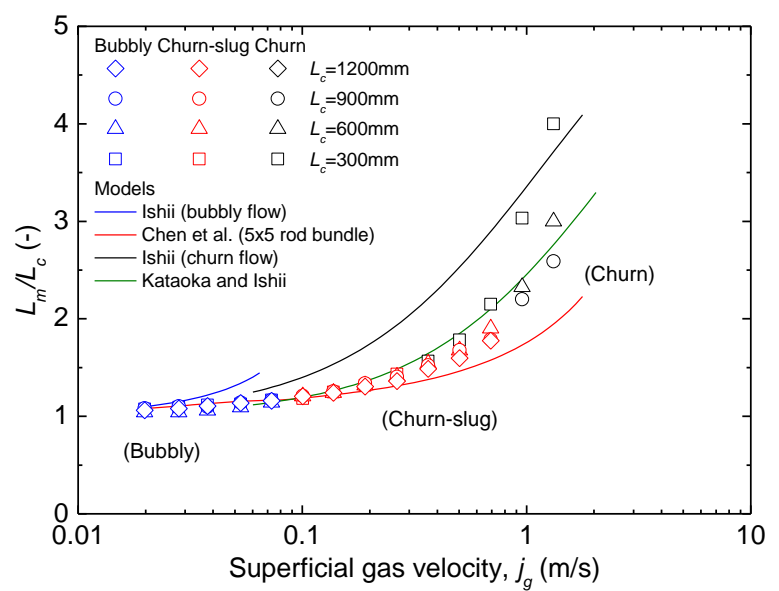

(a) Two-phase mixture level

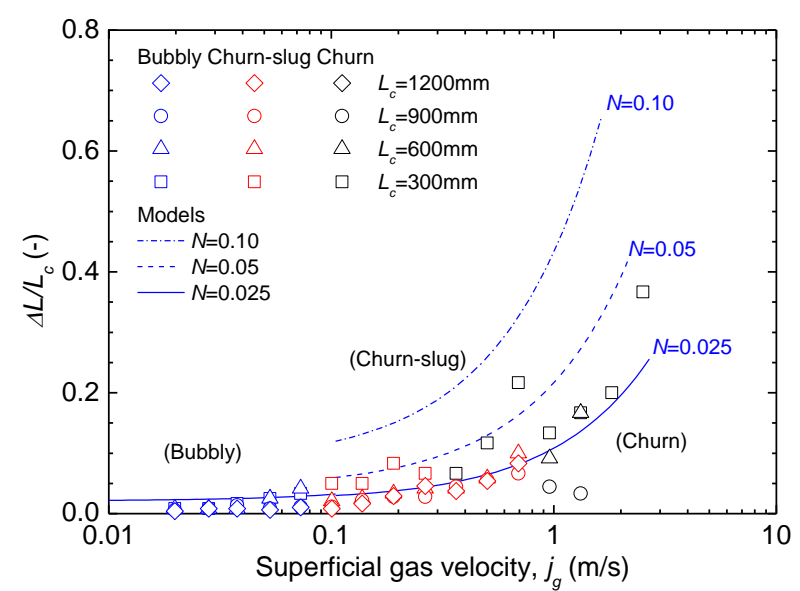

(b) Fluctuation amplitude

Fig. 5 Two-phase mixture level swell in $5 \times 5$ rod bundle.

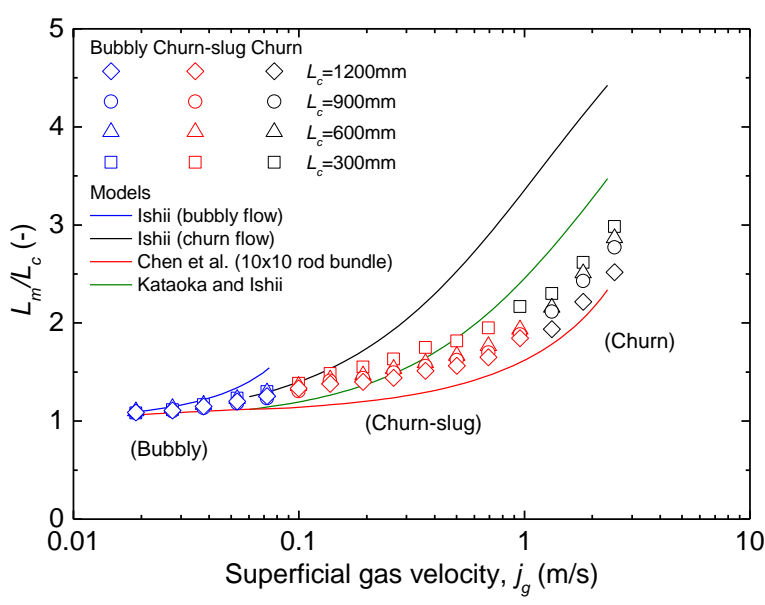

(a) Two-phase mixture level

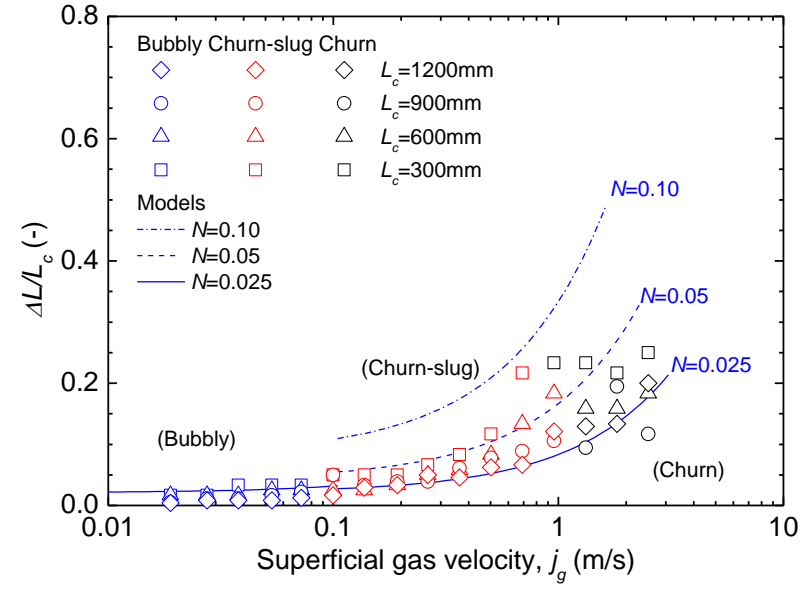

(b) Fluctuation amplitude

Fig. 6 Two-phase mixture level swell in $10 \times 10$ rod bundle.

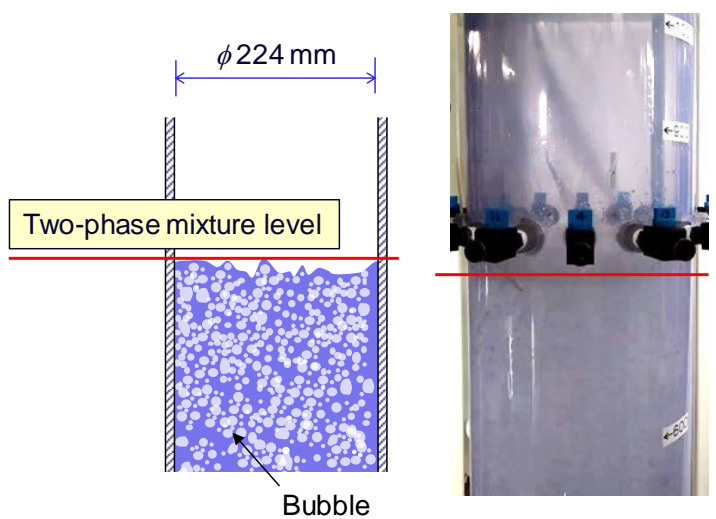

(a) $j_{g}=0.052 \mathrm{~m} / \mathrm{s}$
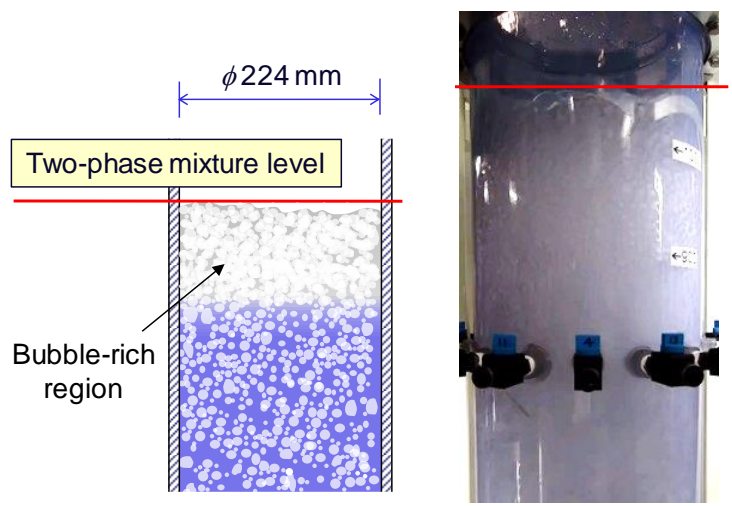

(b) $j_{g}=0.10 \mathrm{~m} / \mathrm{s}$

Fig. 7 The two-phase mixture level in each photograph is indicated by an arrow. When the superficial gas velocity was approximately $0.1 \mathrm{~m} / \mathrm{s}$, a bubble-rich region was observed near the liquid's surface. When the superficial gas velocity further increased, it disappeared due to bubble coalescence, and the two-phase mixture level decreased.

when the channel size was large, the value of $L_{m} / L_{c}$ showed a maximum when the superficial gas velocity was around $0.1 \mathrm{~m} / \mathrm{s}$, particularly in a large-diameter pipe. The two-phase mixture level dropped once when the superficial gas 
velocity exceeded $0.1 \mathrm{~m} / \mathrm{s}$ but increased again as the superficial gas velocity further increased. This tendency was more remarkable at a lower collapsed water level. The maximum value of $L_{m} / L_{c}$ when the superficial gas velocity was approximately $0.1 \mathrm{~m} / \mathrm{s}$ was due to the transition from the bubbly flow to the churn-slug flow. Figure 7 is a flow visualization near the two-phase mixture level in the large-diameter pipe. The two-phase mixture level in each photograph is indicated by a red line. Small bubbles were uniformly dispersed throughout the pool at $j_{g}=0.052 \mathrm{~m} / \mathrm{s}$ corresponding to the bubbly flow. When the superficial gas velocity was approximately $0.1 \mathrm{~m} / \mathrm{s}$, those bubbles remained near the liquid surface and formed a bubble-rich region. When spherical bubbles that were sufficiently smaller than the diameter of the large-diameter pipe were uniformly dispersed to the entire channel, the bubble-rich region was likely to generate at a low initial water level of $L_{c}=300 \mathrm{~mm}$. As the initial water level was higher, those small bubbles coalesced with neighboring ones, and the large bubbles prevented the small bubbles from remaining near the liquid surface. As the superficial gas velocity also increased, those bubbles often coalesced, and the bubble-rich region disappeared due to the intermittent release of the large bubbles from the liquid surface. This condition resulted in the decrease of the value of $L_{m} / L_{c}$. When the superficial gas velocity increased further, the two-phase mixture level increased again. Regarding the fluctuation amplitude of the two-phase mixture level, when the superficial gas velocity increased, the fluctuation amplitude significantly increased due to the flow transition from the bubbly flow to the slug flow in the case of the small-diameter pipe. The experimental values of $\Delta L / L_{c}$ for the small-diameter pipe were within the range of the calculated values of $N=0.025-0.20$. In the large-diameter pipe, the fluctuation amplitude was smaller than that in the small-diameter pipe because no slug bubble covering the entire diameter of the large pipe was formed. Therefore, the experimental values of $\Delta L / L_{c}$ for the large-diameter pipe was within the range of the calculated values of $N=0.025-0.10$.

In the rod bundles, the flow regime transitioned from bubbly flow to churn-slug flow and churn flow with the superficial gas velocity. With the existing two-phase flow experiments in a stagnant pool, the distributions of the void fraction and the gas velocity corresponding to the recirculation were generated (Kataoka et al., 1987; Chen et al., 2004, Chen et al., 2012). The rod bundle has subchannels connected by a narrow channel gap of $3 \mathrm{~mm}$. The cross flow of the bubbles is restrained by the neighboring rods, and the recirculation flow that rises at the center of the flow channel and descends at the peripheral region should be more remarkable. The cross flow increases the drag force as well as the lift force. As the interfacial friction increases, the gas velocity decreases and the void fraction increases. Therefore, when the cross flow was restrained by the rods, the void fraction was relatively small, and the two-phase mixture level in the rod bundle was relatively lower than that in the large-diameter pipe. No slug flow was observed in the rod bundles and the large-diameter pipe. The fluctuation amplitude in the rod bundle was within the range of the calculated values of $N=0.025-0.10$.

Figure 8 is a comparison of the values of $L_{m} / L_{c}$ to the calculated values for circular pipes and rod bundles, respectively. As shown in Figs. 3-6, the two-phase mixture level was summarized by the values of $L_{m} / L_{c}$ as a whole. However, the effect of the initial water level, that is, the axial flow development, was confirmed in the transition from bubbly flow to churn-slug flow or churn flow; thus, the experimental data at larger $L / D$, such as the initial water level of $1200 \mathrm{~mm}$, are plotted to compare with the existing data obtained by Ueda and Koizumi (1993) for small pipes. The circular pipes exhibited a bubbly flow until the superficial gas velocity reached approximately $0.1 \mathrm{~m} / \mathrm{s}$; the experimental results were consistent with the calculated values of Ishii's correlation for bubbly flow. When the superficial gas velocity increased, the channel size affected the values of $L_{m} / L_{c}$ in the slug flow or the churn-slug flow conditions, and the data values of $L_{m} / L_{c}$ increased as the channel size decreased. The effect of channel size on the two-phase mixture level was reproduced by the calculated values of Ishii's correlation for slug flow and Kataoka and Ishii's correlation. The two-phase flow under the pool condition shows an agitated bubble motion, and the size and passage frequency of the slug bubbles are likely to change irregularly even under the slug flow condition in the experiment. This condition causes a variation in the experimental data with respect to the calculated values. In the rod bundles, no significant difference was observed between the values of $L_{m} / L_{c}$ for $5 \times 5$ and $10 \times 10$ bundles because no slug bubble over the entire channel box was sustained. In addition, the values of $L_{m} / L_{c}$ for the rod bundle were relatively smaller than those for the circular pipes and also less than the calculated value of Kataoka and Ishii's correlation for the large-diameter pipe, especially at higher superficial gas velocity. The two-phase flow in the rod bundles under the pool condition shows a recirculation flow due to the existence of the rods. Therefore, the calculated values of Chen et al.'s correlation proposed for a rod bundle reproduced the experimental data. When the superficial gas velocity increased and the flow regime transitioned to churn flow, a difference was observed between the calculated 


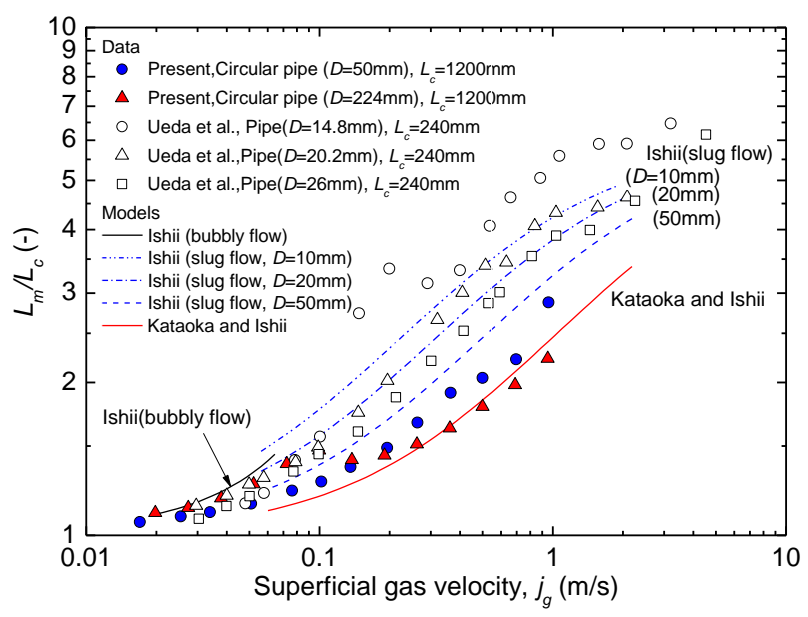

(a) Circular pipes

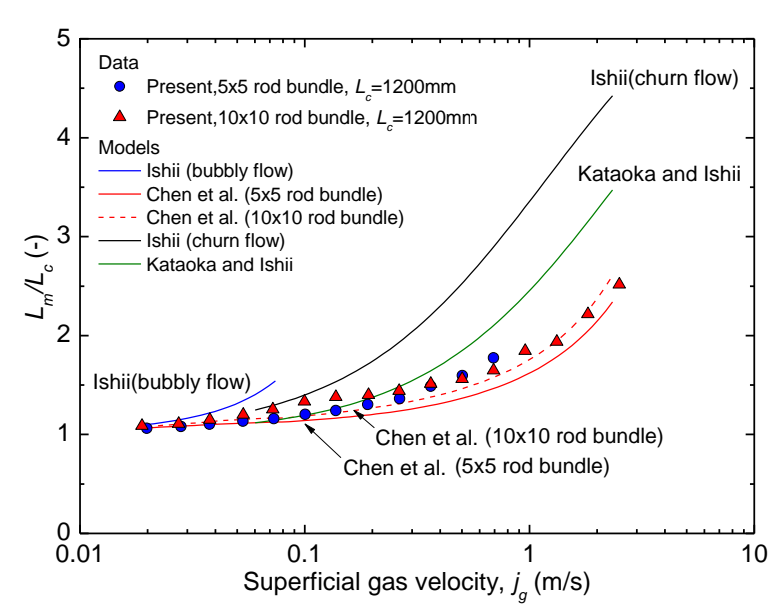

(b) Rod bundles

Fig. 8 Comparison of the two-phase mixture level.

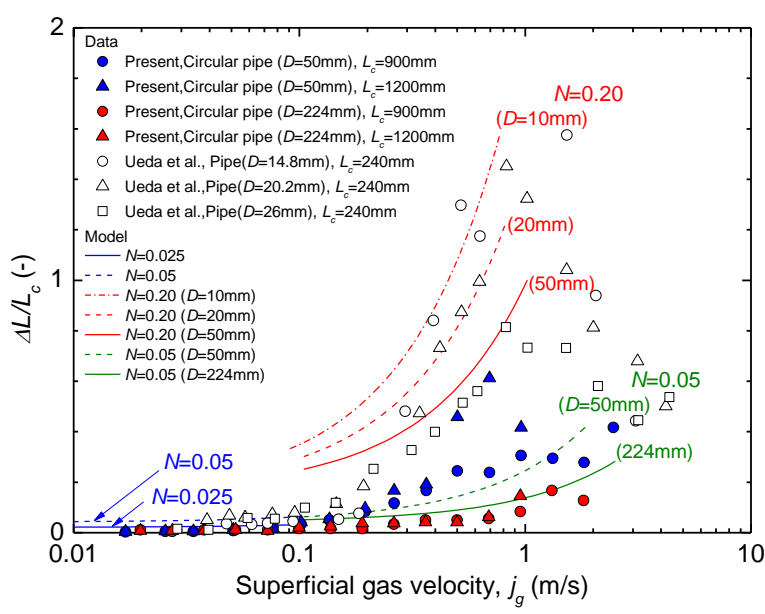

(a) Circular pipes

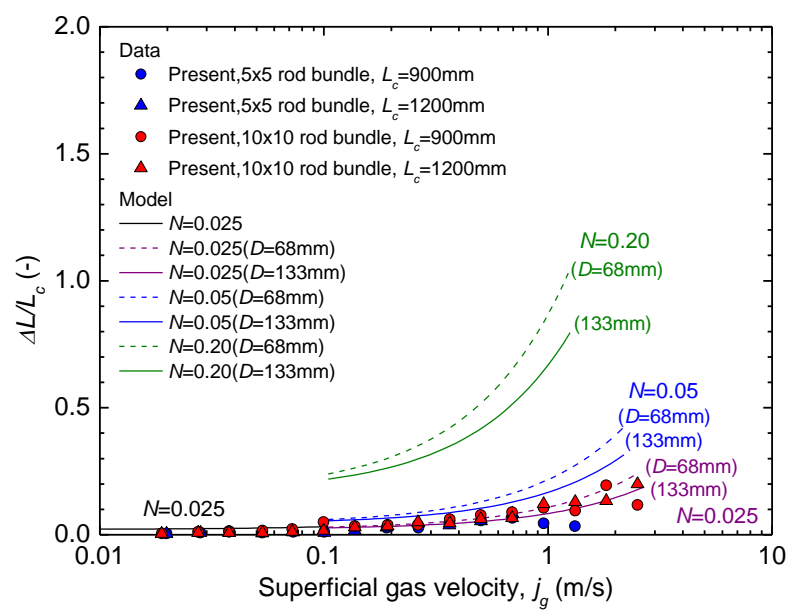

(b) Rod bundles

Fig. 9 Comparison of fluctuation amplitudes of two-phase mixture level.

values and experimental data. The experimental results of the fluctuation amplitude indicate that the axial flow development, or the flow regime transition, affected the difference from the lumped parameter model in the transition to the churn-slug flow or churn flow.

Figure 9 shows a comparison between experimental results and predicted values of $\Delta L / L_{c}$ for circular pipes and rod bundles. As shown in Figs. 3-6, the fluctuation amplitude can be affected by the initial water level because the flow develops from the air mixing region to the liquid surface. To compare the existing experimental data with the present experimental data, the data at larger $L / D$ such as the initial water levels of $900 \mathrm{~mm}$ and $1200 \mathrm{~mm}$ are plotted. When the pipe diameter was $50 \mathrm{~mm}$ or less, the fluctuation amplitude tended to decrease due to the transition from slug flow to churn flow around the superficial gas velocity of $1.0 \mathrm{~m} / \mathrm{s}$. This study focused on the fluctuation characteristics until the maximum value was reached (i.e., the bubbly flow to the slug flow or churn-slug flow) and compared the experimental results with the calculated values. In the circular pipe, the values of $\Delta L / L_{c}$ were close to the calculated value of $N=0.025$ in the bubbly flow region. When the superficial gas velocity exceeded $0.1 \mathrm{~m} / \mathrm{s}$, the values of $\Delta L / L_{c}$ were greater as the pipe diameter decreased. Slug flow was observed in the circular pipes with a diameter of $50 \mathrm{~mm}$ or less, and the calculated values for slug flow reproduced the effect of the pipe diameter on the experimental data. In addition, there was a difference in the fluctuation amplitude between the initial liquid levels of 900 and $1200 \mathrm{~mm}$ when the pipe diameter was $50 \mathrm{~mm}$. In the experiment, the pipe diameter of $50 \mathrm{~mm}$ was a criterion for the flow transition to determine whether the bubble size released from the liquid surface reached the pipe diameter. When the initial water level was $1200 \mathrm{~mm}$, the slug bubbles covering the entire diameter of the pipe were formed, and the experimental data were close 
to the calculated values corresponding to slug flow. In the case of the rod bundles, the experimental values of $\Delta L / L_{c}$ in the bubbly flow region almost agreed with the calculated values of $N=0.025$ as well as the circular pipe cases. The experimental values of $\Delta L / L_{c}$ in the churn-slug flow region were within the range of the calculated values of $N=0.025-0.05$. At a faster superficial gas velocity, the experimental values of $\Delta L / L_{c}$ for the rod bundles were smaller than that for the small diameter pipe. Generally, when the superficial gas velocity increases, large bubbles over multiple subchannels are dominant. In the rod bundles, however, the cross flow and bubble coalescence are restricted by the rods. It is difficult to form a slug bubble over the entire channel box, and the bubbles are randomly released from the liquid surface of each subchannel; thus, the fluctuation amplitude is relatively small.

Consequently, this result indicates that the fluctuation amplitude of the two-phase mixture level when there was sufficient initial water level for the pipe diameter and the channel box dimension was organized with the calculated values of $N=0.025-0.05$ regardless of the channel geometries and dimensions in the bubbly flow region. When the superficial gas velocity further increased, the experimental results with a pipe diameter of $50 \mathrm{~mm}$ or less were close to the calculated values corresponding to slug flow. On the other hand, when slug bubbles were not sustained as in the case of the rod bundles or the large-diameter pipe, the random or intermittent passage of bubbles smaller than the channel size, such as the pipe diameter or the internal dimension of the channel box, was dominant. Therefore, the fluctuation amplitude in the churn-slug flow and the churn flow regions were in the range of the calculated values of $N=0.025-0.10$. The parameter $N$ in the original model includes a bubble plug size and its frequency. To improve the prediction accuracy of the two-phase mixture level fluctuation, further investigations are needed to consider the dominant bubble size and the frequency of released bubbles according to the flow channel geometries and flow conditions.

\section{Conclusions}

When air was mixed with stagnant water in vertical pipes with diameters of 50 and $224 \mathrm{~mm}$ and in $5 \times 5$ and $10 \times 10$ rod bundles, the two-phase mixture level swell corresponded with an increase in the superficial gas velocity. In all channel geometries, the experimental results of the two-phase mixture level were organized by the values of $L_{m} / L_{c}$ and exhibited flow characteristics dependent on the channel geometries and flow conditions. Since the values of $L_{m} / L_{c}$ for different collapsed water levels were almost the same for all channel geometries in the bubbly flow region, the influence of the initial liquid level on the two-phase mixture level was found to be small. The experimental values of $L_{m} / L_{c}$ show an agreement with the calculated values for bubbly flow regardless of the channel configurations. When the flow regime transitioned from bubbly flow to slug flow, the influence of the channel geometries and dimensions on the two-phase mixture level was significant. Slug flow was observed in the circular pipes with a diameter of $50 \mathrm{~mm}$ or less, and the calculated values for slug flow reproduced the effect of the pipe diameter on the two-phase mixture level. On contrary, no slug bubble was sustained in the rod bundles and the large-diameter pipe, and the flow regime transitioned from bubbly flow to churn-slug flow with the superficial gas velocity. The experimental values of $L_{m} / L_{c}$ for the large pipe and the rod bundles were reproduced with the calculated values according to the channel size and geometry. Regarding the fluctuation amplitude, the experimental values of $\Delta L / L_{c}$ in the bubbly flow region were within the calculated values of $N=0.025-0.05$ regardless of the channel geometries and dimensions. When the superficial gas velocity increased, the experimental values of $\Delta L / L_{c}$ were remarkably large especially in the small-diameter pipes with a diameter of $50 \mathrm{~mm}$ or less and were within the range of the calculated values of $N=0.025-0.20$. On the other hand, when slug bubbles were not sustained as in the case of the rod bundles or the large-diameter pipe, the random or intermittent passage of bubbles smaller than the channel size was dominant in the churn-slug flow region. Therefore, the experimental values of $\Delta L / L_{c}$ were within the range of the calculated values of $N=0.025-0.10$.

\section{Acknowledgments}

The authors would like to thank Messrs. Takio Endo, Yoshiyuki Shiratori, Yuki Miyazawa, and Shinya Ueno of Electric Power Engineering Systems Co., Ltd. for helping with the experiments. 


\section{References}

Anklam, T.M. and Miller, R.F., Void fraction under high pressure, low flow conditions in rod bundle geometry, Nuclear Engineering and Design, Vol.75 (1983), pp. 99-108.

Arai, T., Furuya, M., Kanai, T., Shirakawa, K. and Nishi, Y., Boiled-up level and boiling two-phase flow dynamics in $5 \times 5$ heated rod bundle during boil-off process under atmospheric pressure conditions, Proceedings of 16 th International Topical Meeting on Nuclear Reactor Thermal Hydraulics (NURETH-16) (2015a), pp. 7312-7322.

Arai, T., Furuya, M., Kanai, T., Shirakawa, K. and Nishi, Y., Coolability height of $5 \times 5$ heated rod bundle in reference to collapsed level and boiling two-phase flow dynamics, Proceedings of the 23rd International Conference on Nuclear Engineering (ICONE-23) (2015b), Paper No. ICONE23-1551.

Arai, T., Furuya, M., Takiguchi, H., Nishi, Y. and Shirakawa, K., X-ray radiography for two-phase mixture level fluctuation during boil-off in rod bundle for wide pressure range, Proceedings of 18th International Topical Meeting on Nuclear Reactor Thermal Hydraulics (NURETH-18) (2019), pp. 5701-5708.

Chen, S.W., Liu, Y., Hibiki, T., Ishii, M., Yoshida, Y., Kinoshita, I., Murase, M., Mishima, K., Experimental study of air-water two-phase flow in an $8 \times 8$ rod bundle under pool condition for one-dimensional drift-flux analysis, Int. J. Heat Fluid Flow. Vol.33 (2012a), pp.168-181.

Chen, S. W., Liu, Y., Hibiki, T., Ishii, M., Yoshida, Y., Kinoshita, I., Murase, M. and Mishima, K., One-dimensional drift-flux model for two-phase flow in pool rod bundle system/s, International Journal of Multiphase Flow, Vol.40, (2012b), pp.166-177.

Ishii, M., One-dimensional drift-flux model and constitutive equations for relative motion between phases in various two-phase flow regimes, ANL-77-47 (1977).

Kamei, A., Hosokawa, S., Tomiyama, A., Kinoshita, I. and Murase, M., Void fraction in a four by four rod bundle under a stagnant condition, Journal of Power and Energy Systems, Vol.4, No.2 (2010), pp.315-326.

Kataoka, I., Ishii, M., Drift flux model for large diameter pipe and new correlation for pool void fraction, International Journal of Heat and Mass Transfer, Vol.30 (1987), pp. 1927-1939.

Kinoshita, I., Torige, T., Yamada, M., Hibiki, T., Development and validation of a new drift flux model in rod bundle geometries, Proceedings of International Topical Meeting on Nuclear Reactor Thermal Hydraulics (NURETH-16) (2015), pp. 1130-1142.

Kumamaru, H., Kondo, M., Murata, H. and Kukita, Y., Void-fraction distribution under high-pressure boil-off conditions in rod bundle geometry, Nuclear Engineering and Design, Vol.150 (1994), pp. 95-105.

Liu, H., Hibiki, T., Flow regime transition criteria for upward two-phase flow in vertical rod bundles, International Journal of Heat and Mass Transfer, Vol. 108 (2017), pp. 423-433.

Mishima, K., Ishii, M., Flow regime transition criteria for upward two-phase flow in vertical tubes, International Journal of Heat and Mass Transfer, Vol. 27 (1984), pp. 723-737.

Mizutani, Y., Hosokawa, S., Tomiyama, A., Two-phase flow patterns in a four by four rod bundle, Proceedings of 14th International Conference on Nuclear Engineering (ICONE-14) (2006), Paper No. ICONE14-89332.

Ohnuki, A., Akimoto, H., Experimental study on transition of flow pattern and phase distribution in upward air-water two-phase flow along a large vertical pipe, International Journal of Multiphase Flow, Vol. 26 (2000), pp. $367-386$.

Osakabe, M., Koizumi, Y. and Tasaka, K., Interfacial drag coefficient of air-water mixture in rod bundle, Journal of Nuclear Science and Technology, Vol.21, No.11 (1984), pp.882-884.

Paranjape, S., Stefanczyk, D., Liang, Y., Hibiki, T., Ishii, M., Global flow regime identification in a rod bundle geometry, Proceedings of 16th International Conference on Nuclear Engineering (ICONE-16) (2008), Paper No. ICONE16-48435.

Qazi, M.K., Guido-Lavalle, G. and Clausse, A., Void fraction along a vertical heated rod bundle under flow stagnation conditions, Nuclear Engineering and Design, Vol.152 (1994), pp. 225-230.

Schlegel, J.P., Sawant, P., Paranjape, S., Ozar, B., Hibiki, T., Ishii, M., Void fraction and flow regime in adiabatic upward two-phase flow in large diameter vertical pipes, Nuclear Engineering and Designs, Vol.239 (2009), pp. 2864-2874.

Seedy, D.S. and Muralidhoran, R., BWR low-flow bundle uncovery test and analysis, EPRI NP-1781; GEAP-24964; NUREG/CR-2231 (1982).

Shires, G.L., Pearson, K.G. and Richards, A.D, An experimental study of level swell in a partially water filled fuel 
cluster, Nuclear Energy, Vol.19 (1980), pp. 381-388.

Suzuki, H. and Murase, M., Countercurrent Air-water flow in two vertical channels, Journal of Nuclear Science and Technology, Vol.23, No.5 (1986), pp.461-468.

Ueda, T. and Koizumi, Y., Two-phase mixture level swell in vertical pipes, International Journal of Multiphase Flow, Vol.19, No.1 (1993), pp.1-13.

Zuber, N. and Findlay, J. A., Average volumetric concentration in two-phase flow systems, Journal of Heat Transfer, Vol.87, No.4 (1965), pp. 453-468. 